\title{
What are the Consequences of Volume Expansion in Chronic Dialysis Patients?
}

\author{
Hypertension as a Manifestation of Volume Overload in Hemodialysis Patients \\ Rajiv Agarwal \\ Division of Nephrology, Indiana University School of Medicine and VA Medical Center, Indianapolis, Indiana
}

Volume overload in the dialysis patient is easy to recognize when it presents itself emergently as shortness of breath. However, overt signs and symptoms of heart failure such as an elevated jugular venous pressure, displaced cardiac apex, third or fourth left ventricular heart sounds, hepatomegaly, and edema are often a late manifestation of volume overload. More often, volume excess is covert. In this review, I will discuss hypertension as a manifestation of volume overload.

Elevated blood pressure documented between dialysis treatments is an early manifestation of volume overload. Increase in volume results in an increase in cardiac output. This increase in cardiac output culminates in increased systemic vascular resistance and consequently hypertension. The prevalence of hypertension, among 369 chronic HD patients defined by either an 44-hour interdialytic ambulatory BP of $135 / 85 \mathrm{mmHg}$ or more or the prescription of any antihypertensive agent, was $86 \%$ (1). Although hypertension was being treated with antihypertensive drugs in $89 \%$, it was adequately controlled only in $38 \%$.

Among patients who have essential hypertension with kidney disease, we commonly accept diuretic responsive hypertension to be due to excess volume. We do not require manifestations of volume excess such as pedal edema, elevated jugular venous pressure, displaced cardiac apex or other signs of volume overload before diagnosing volume-responsive hypertension. Similarly, among hypertensive dialysis patients we should not require overt signs of vol-

Address correspondence to: Rajiv Agarwal, M.D., Professor of Medicine, Division of Nephrology, Department of Medicine, Indiana University and RLR VA Medical Center, 1481 West $10^{\text {th }}$ Street, $111 \mathrm{~N}$, Indianapolis, IN 46202, Tel.: 317554 0000 x 2241, Fax: 317554 0298, or

e-mail: ragarwal@iu.edu.

Seminars in Dialysis—Vol 28, No 3 (May-June) 2015 pp. 231-232

DOI: $10.1111 /$ sdi. 12349

Published 2015. This article is a U.S. Government work and is in the public domain in the USA. ume overload to diagnose volume-responsive hypertension. Studies suggest that the presence or absence of edema, which is often taken to be as a reliable sign of volume overload, has no predictive value in separating the responders from nonresponders with dry-weight reduction (2). Perhaps the best evidence for hypertension being a manifestation of volume excess comes from the dry-weight reduction in hypertensive dialysis patients (DRIP) trial (2).

In this randomized controlled trial dry-weight was probed without changing dialysis time (2). This study tested the hypothesis that hypertension among HD patients who do not manifest overt signs of volume overload is mediated by excess volume; accordingly, patients with obvious volume overload were excluded. In this trial, 50 patients were randomized to a control group and 100 patients randomized to ultrafiltration group and all underwent interdialytic ambulatory blood pressure monitoring three times (at baseline, 4 weeks, and 8 weeks). Despite stable concurrent use of 2.7 antihypertensive drugs, in the ultrafiltration group, the ambulatory BP was reduced within 4 weeks by $11 / 6 \mathrm{mmHg}$ (2) After correcting for the placebo effect seen in the control group ambulatory BP reduction in the ultrafiltration group remained significant at $7 / 3 \mathrm{mmHg}$. This antihypertensive effect was sustained for 8 weeks of observation. Despite provoking occasional uncomfortable intradialytic symptoms, the quality of life was not impaired with reducing dry weight. Often overlooked is the fact that in this trial, $10 \%$ of the patients in the control group developed accelerated hypertension (defined as $\mathrm{BP} \geq 175 / 105 \mathrm{mmHg}$ by interdialytic ambulatory monitoring). This study strongly supports the hypothesis that, hypertension is a manifestation of volume excess among HD patients. Furthermore, lack of attention to dry-weight can result is severe elevations in interdialytic blood pressure in one of ten patients.

In clinical practice, hypertension is perhaps best detected by performing blood pressure monitoring 
at home over a few days $(3,4)$. Home BP monitoring is recommended by several societies $(5,6)$ but is especially valuable in diagnosing and managing hypertension among patients on dialysis (7). Home BP correlates more closely with ambulatory BP than does predialysis or postdialysis BP recordings (8). It can track changes in BP evoked by reduction in dry-weight and is much more reproducible from one week to the next compared to predialysis or postdialysis BP recordings (9). Home BP is superior to measurements made in the dialysis unit (even using recommended techniques) in predicting the presence of target organ damage (echocardiographic left ventricular hypertrophy) $(10,11)$ and long-term outcomes such as cardiovascular events (12) or mortality (12-15). A randomized trial suggests that among long-term dialysis patients, home BP guided antihypertensive therapy can better achieve hypertension control at 6 months than antihypertensive therapy guided by predialysis BP (16). Another trial randomized $17 \mathrm{HD}$ patients to usual care and 17 to home BP monitoring; average weekly systolic BP improved only in the home BP group (17). These data support the use of home BP measurement to diagnose and treat hypertension among patients on HD.

Among HD patients, the timing and frequency of home BP monitoring is of particular importance. Home BP increases on average at a rate of $4 \mathrm{mmHg}$ every 10 hours elapsed after dialysis (18). Therefore, measurement soon after dialysis or just before dialysis will underestimate or overestimate the burden of hypertension. Therefore, it is important to measure $\mathrm{BP}$ at various intervals following dialysis. Measurements made twice daily (on waking up in the morning and just before going to sleep) following a mid-week dialysis for 4 days (19) are practical ways to follow patients over time.

Another indicator of volume overload in a dialysis patient is the use of multiple antihypertensive drugs. If blood pressure remains uncontrolled after full doses of three antihypertensive drugs, it is quite likely that volume excess is present. The knee-jerk response to elevated blood pressure in a dialysis patient of increasing the number of antihypertensive drugs is likely to fail if volume overload is not adequately addressed. In a cross-sectional study of 369 patients at one center, the independent determinants of poor control were the use of antihypertensive drugs and an expanded extracellular volume state (1). In longitudinal follow up, if patients were volume overloaded, nearly $80 \%$ became hypertensive when medications were withdrawn. Paradoxically, the more medications the patients received, the more likely they were to be hypertensive.
In conclusion, volume excess often manifests as hypertension in dialysis patients and volume reduction is a practical way to lower BP among such patients.

\section{References}

1. Agarwal R: Epidemiology of interdialytic ambulatory hypertension and the role of volume excess. Am J Nephrol 34(4):381-390, 2011

2. Agarwal R, Alborzi P, Satyan S, Light RP: Dry-weight reduction in hypertensive hemodialysis patients (DRIP): a randomized, controlled trial. Hypertension 53(3):500-507, 2009

3. Agarwal R: Role of home blood pressure monitoring in hemodialysis patients. Am J Kidney Dis 33(4):682-687, 1999

4. Agarwal R, Peixoto AJ, Santos SF, Zoccali C: Out-of-office blood pressure monitoring in chronic kidney disease. Blood Press Monit 14 (1):2-11, 2009

5. Pickering TG, Miller NH, Ogedegbe G, Krakoff LR, Artinian NT, Goff D: Call to action on use and reimbursement for home blood pressure monitoring: a joint scientific statement from the American Heart Association, American Society Of Hypertension, and Preventive Cardiovascular Nurses Association. Hypertension 52(1):10-29, 2008

6. Parati G, Stergiou GS, Asmar R, Bilo G, de Leeuw P, Imai Y, Kario K, Lurbe E, Manolis A, Mengden T, O'Brien E, Ohkubo T, Padfield P, Palatini P, Pickering T, Redon J, Revera M, Ruilope LM, Shennan A, Staessen JA, Tisler A, Waeber B, Zanchetti A, Mancia G: European Society of Hypertension guidelines for blood pressure monitoring at home: a summary report of the Second International Consensus Conference on Home Blood Pressure Monitoring. J Hypertens 26 (8):1505-1526, 2008

7. Agarwal R: Managing hypertension using home blood pressure monitoring among haemodialysis patients-a call to action. Nephrol Dial Transplant 25(6): 1766-1771, 2010

8. Agarwal R, Andersen MJ, Bishu K, Saha C: Home blood pressure monitoring improves the diagnosis of hypertension in hemodialysis patients. Kidney Int 69(5):900-906, 2006

9. Agarwal R, Satyan S, Alborzi P, Light RP, Tegegne GG, Mazengia HS, Yigazu PM: Home blood pressure measurements for managing hypertension in hemodialysis patients. Am J Nephrol 30(2):126-134, 2009

10. Agarwal R, Brim NJ, Mahenthiran J, Andersen MJ, Saha C: Out-ofhemodialysis-unit blood pressure is a superior determinant of left ventricular hypertrophy. Hypertension 47(1):62-68, 2006

11. Moriya H, Ohtake T, Kobayashi S: Aortic stiffness, left ventricular hypertrophy and weekly averaged blood pressure (WAB) in patients on haemodialysis. Nephrol Dial Transplant 22(4):1198-1204, 2007

12. Moriya H, Oka M, Maesato K, Mano T, Ikee R, Ohtake T, Kobayashi S: Weekly averaged blood pressure is more important than a single-point blood pressure measurement in the risk stratification of dialysis patients. Clin J Am Soc Nephrol 3(2):416-422, 2008

13. Amar J, Vernier I, Rossignol E, Bongard V, Arnaud C, Conte JJ, Salvador M, Chamontin B: Nocturnal blood pressure and 24-hour pulse pressure are potent indicators of mortality in hemodialysis patients. Kidney Int 57(6):2485-2491, 2000

14. Alborzi P, Patel N, Agarwal R: Home blood pressures are of greater prognostic value than hemodialysis unit recordings. Clin J Am Soc Nephrol 2(6):1228-1234, 2007

15. Agarwal R: Hypervolemia is associated with increased mortality among hemodialysis patients. Hypertension 56(3):512-517, 2010

16. da Silva GV, de Barros S., Abensur H, Ortega KC, Mion D Jr: Home blood pressure monitoring in blood pressure control among haemodialysis patients: an open randomized clinical trial. Nephrol Dial Transplant 24(12):3805-3811, 2009

17. Kauric-Klein Z, Artinian N: Improving blood pressure control in hypertensive hemodialysis patients. CANNT J 17(4):24-26, 2007

18. Agarwal R, Light RP: Chronobiology of arterial hypertension in hemodialysis patients: implications for home blood pressure monitoring. Am J Kidney Dis 54(4):693-701, 2009

19. Agarwal R, Andersen MJ, Light RP: Location not quantity of blood pressure measurements predicts mortality in hemodialysis patients. Am $J$ Nephrol 28(2):210-217, 2007 